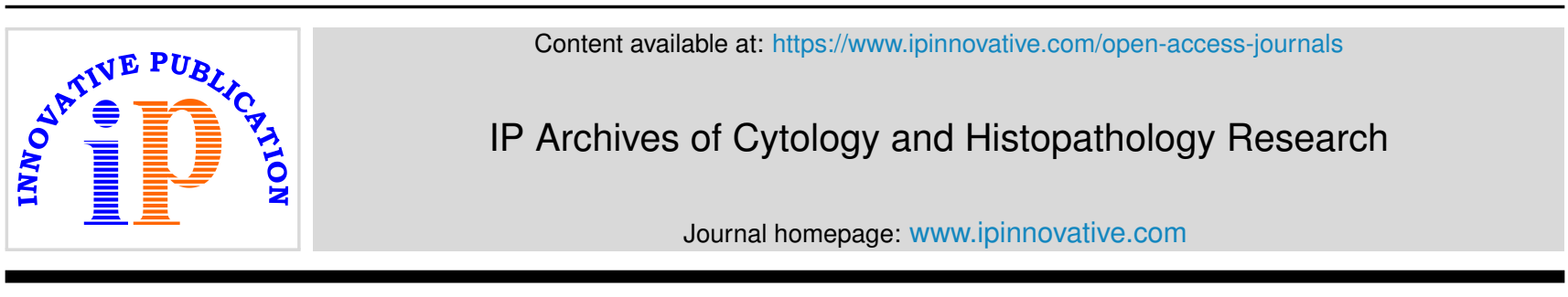

Original Research Article

\title{
Analysis of Pleural fluid cytology: A one year study in tertiary care centre
}

\author{
Lekha M B ${ }^{1, *}$, Manjunatha $Y A^{\mathbf{1}}$ \\ ${ }^{1}$ Dept. of Pathology, Dr. B.R. Ambedkar Medical College, Bangalore, Karnataka, India
}

\section{A R T I C L E I N F O}

Article history:

Received 07-05-2020

Accepted 10-09-2020

Available online 20-10-2020

\section{Keywords:}

Body fluid

Pleural fluid

Cytology

Tuberculosis

Malignancy

\begin{abstract}
A B S T R A C T
Introduction: Cytological analysis of pleural fluid is a simple, rapid and initial investigation serving both as diagnostic and therapeutic measure.

Materials and Methods: The present prospective analysis was carried out in the Department of Pathology in Dr B R Ambedkar Medical College and Hospital, Bangalore, from Jan 2018 to Dec 2018 on pleural fluids samples.

Results: Out of 120 pleural fluid analysis, maximum bulk of patients was seen in 5th decade with M:F ratio of 1.5:1. Majority of effusion were non neoplastic accounting to $88.33 \%$ with chronic inflammation accounting $82 \%$ and Tuberculous effusion was seen in 13 cases.

Conclusion: The present study highlights the importance of cytological analysis of pleural fluid as a complete diagnostic investigation which also in helps at pointing out the cause and follow up of disease process.
\end{abstract}

(C) 2020 Published by Innovative Publication. This is an open access article under the CC BY-NC license (https://creativecommons.org/licenses/by-nc/4.0/)

\section{Introduction}

Cytological analysis of body fluids is most simple and initial investigation done as preliminary step for the diagnostic evaluation of body fluids, helping the physician in clinching the diagnosis. It provides us various information regarding pathological processes such as whether infection or reactive process and also to rule out the presence of neoplasm. Most commonly analysed fluids are pleural, ascitic, pericardial and occasionally peritoneal fluid/wash. The other fluids which are analysed are synovial, pericardial. Less frequently analysed fluids are urine, sputum nipple discharges and endometrial aspirates. ${ }^{1}$

Body cavities (pleura, peritoneum) have a common embryologic origin in the mesenchymal embryonic layer and are lined by mesothelial cells. Their support system is appropriate connective tissue, vascular and nervous apparatus. Parietal and visceral layer are separated by thin layer of lubricating fluid that provides the movement of two membranes against each other in the absence of

\footnotetext{
* Corresponding author.

E-mail address: dr_lekha@rediffmail.com (Lekha M B).
}

disease. ${ }^{2}$ Accumulation of fluid in the body cavities occurs due to imbalance between formation and removal of fluid as stated by Starling's law. Pleural fluid is one of most common body fluid to be received in cytology department. The study of pleural fluid cytology has paramount importance in identifying atypical cells in effusions which in turn helps to know

The present study was undertaken in our setup to examine the cytomorphology of pleural using conventional smears, and to give cytological diagnosis of fluid examination thus evaluating the diagnostic accuracy of cytological analysis of fluids.

\section{Materials and Methods}

This is prospective observational analysis of pleural fluid cytology in the Department of Pathology, Dr B R Ambedkar Medical College and Hospital, Banglore for duration of one year from Jan 2018 to Dec 2018. All the cases of Benign and Malignant serous effusions from pleura received from various departments in our institute were included in the study. All other fluids were excluded. 
The fluid samples were examined for physical properties first like the volume, color, appearance, turbidity, presence of clot coagulum followed by centrifugation at $2000 \mathrm{rpm}$ for five minutes. Smears were then made from the sediment part of centrifuged fluid and stained with Giemsa, Hematoxylineosin and Papanicolaou stains. Smears were examined for the total cell count, differential cell count and reported descriptively. Malignant pleural effusions were further classified according to its cytomorphological features. Study results were then analyzed with the help of tables and charts and discussed for its incidence rate.

\section{Results}

In our present study cytological analysis was done for 120 pleural fluid. The male to female ratio was $1.5: 1$ with 72 cases of Male patients and 48 cases of Female patient.

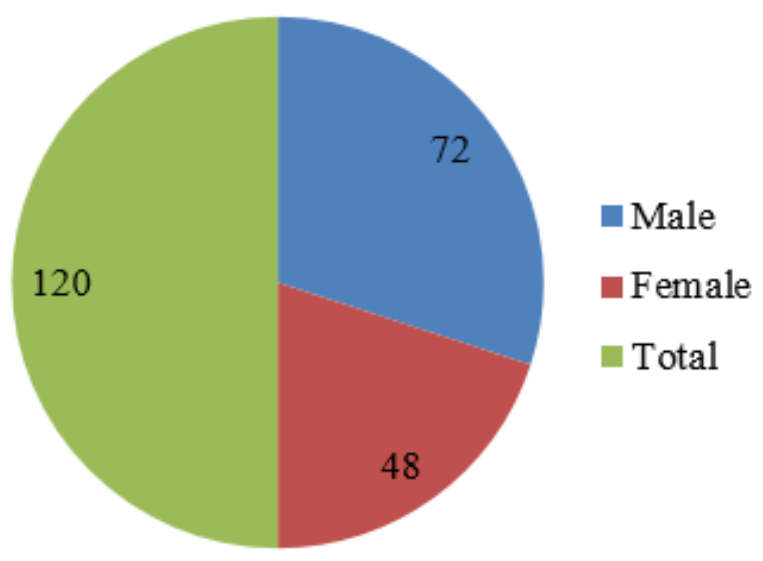

Fig. 1: Distribution of pleural effusions based on sex.

The age ranged from 7 years to 93 years with maximum bulk being in the age group of $41-50$ years.

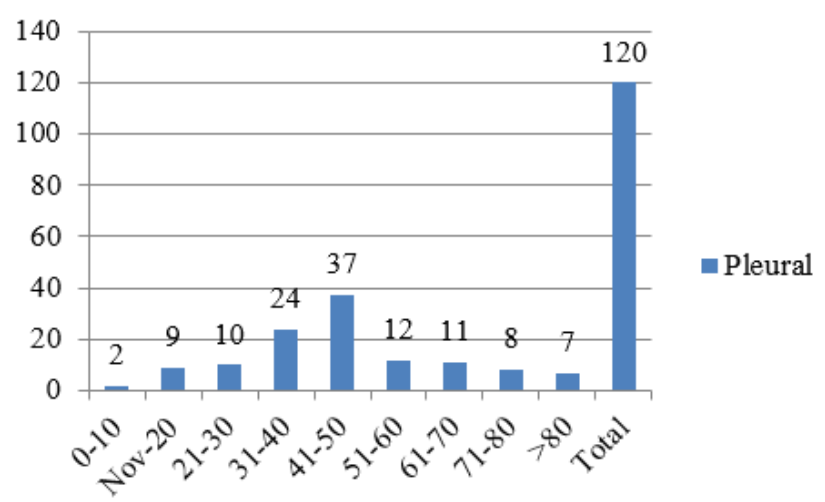

Fig. 2: Age - wise distribution of Pleural effusions.

Out of 120 cases, majority of cases were right sided effusion accounting to 68 cases, followed by 34 cases of left sided effusion and in 18 cases there were bilateral effusion.

In the present study, majority of effusion were non neoplastic accounting to 106 cases $(88.33 \%)$ and neoplastic effusion accounting to 8 cases $(6.66 \%)$.

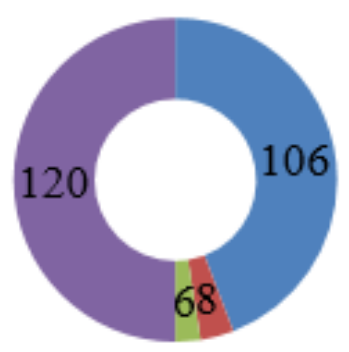

\section{- Non neoplastic Neoplastic}

\section{Scant cellularity $n$ Total}

Fig. 3: Distribution of Neoplastic Vs Non neoplastic causes of pleural effusion

Among non neoplastic lesions maximum cases were of chronic inflammation accounting $82 \%$ followed by changes of acute inflammation and reactive changes. Out of 63 cases of chronic inflammation 13 cases were suggestive of tuberculous inflammation characterized by lymphocytes rich effusion. And majority of pleural effusions were transduative in nature accounting to $62.5 \%$.

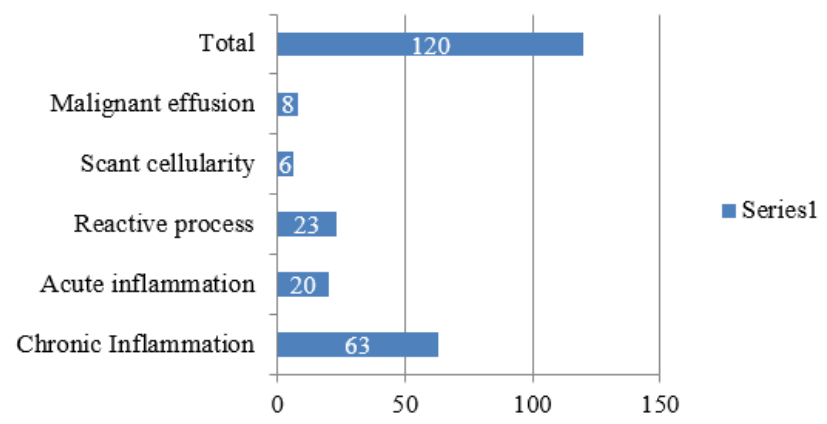

Fig. 4: Distribution of various causes of Pleural effusion.

Malignant pleural effusions were seen in 8 cases $(6.66 \%)$ out of which, 5 cases $(60 \%)$ were metastatic adenocarcinoma and remaining pleural effusions have nonspecific malignant cells effusions

\section{Discussion}

For decades, body fluid analysis has played an important role as a diagnostic aid in establishing a definitive diagnosis, predicting prognosis and planning or monitoring therapy. 
It has gained increased acceptance in clinical practice today, since it is relatively simple, safe and inexpensive procedure. ${ }^{3}$

Pleural effusions are caused by both pulmonary or nonpulmonary diseases. Although the etiologic spectrum is wide, most effusions occur due to malignancy, heart failure, tuberculosis or bacterial infection. ${ }^{4}$

Analysis of body fluid cytology at times becomes very tedious as morphology of reactive mesothelial cells may mimic malignant cells. Hence, distinction between these two on cytological examination of effusion cytology is always a diagnostic challenge. The present study was undertaken to analyse the trends of pleural effusions in our institute and to study the importance of fluid cytology in the diagnosis of various benign and malignant conditions.

We had total of 120 cases in our study. Male comprised the majority with male to female ratio of $1.5: 1$, which is in concordance with studies conducted by Gojiya $\mathrm{P},{ }^{5}$ Rasik Hathila et al, ${ }^{6}$ Priyanka Kiyawat et al ${ }^{7}$ and Ishan Arora et al. ${ }^{8}$

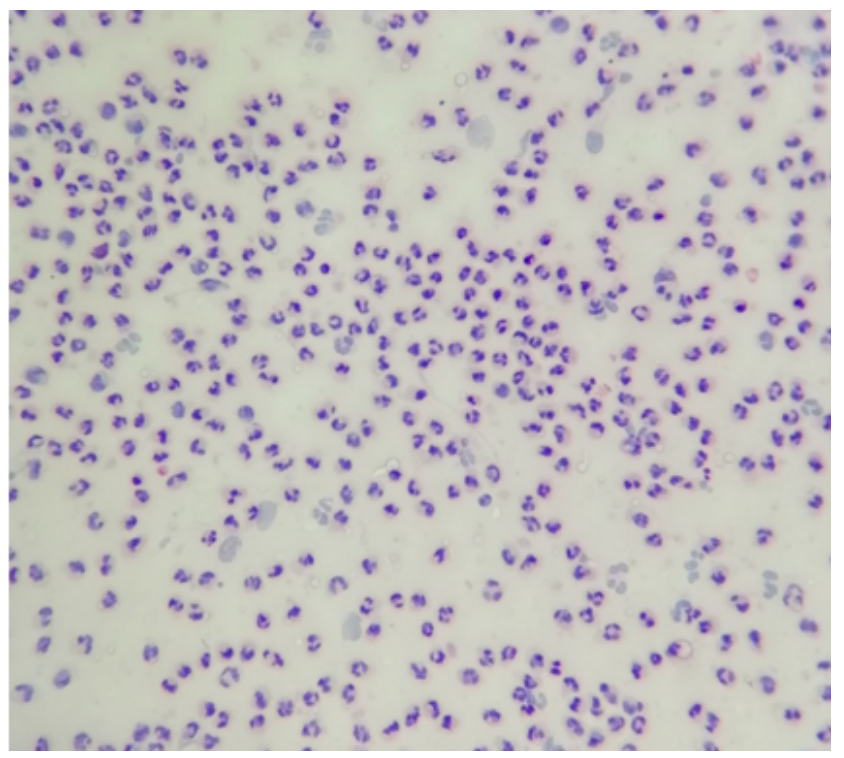

Fig. 5: Centrifuged smear shows predominance of neutrophils Acute Inflammation.

Differentiation from transudate on routine examination of fluid is mainly based on levels of protein (Transudate less than $3 \mathrm{gm} \%$ and exudate more than $3 \mathrm{gm} \%$ ), Rasik Hathila et $\mathrm{al}^{6}$ and Priyanka Kiyawat et $\mathrm{al}^{7}$ had similar finding. On the cytological examination,transudative effusions are usually characterised by a majority of lymphocytes or other mononuclear cells. In our study majority were tranduative in nature.

In pleural fluid samples, non- neoplastic cases formed the majority $(88.33 \%)$, whereas neoplastic cases made up 6.66 $\%$ of the total which is in concordance with Gojiya $\mathrm{P}^{6}$ and Ishan Arora et al. ${ }^{8}$

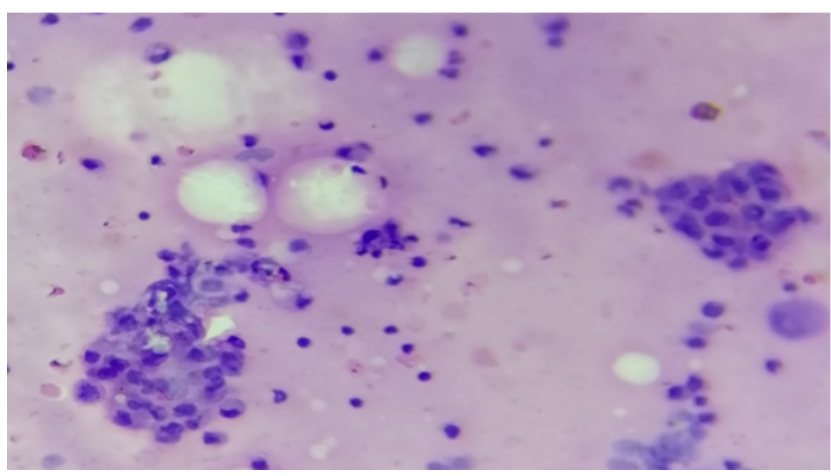

Fig. 6: Centrifuged smear shows reactivemesothelial cells in background of lymphocytes.

Among the non neoplastic cases, majority were due to chronic inflammation. A study done Prasad Rajan ${ }^{9}$ also showed chronic inflammatory lesion most common, similar to our study. And they also reported low percentage of Tuberculosis in pleural fluid which was similar to our study.

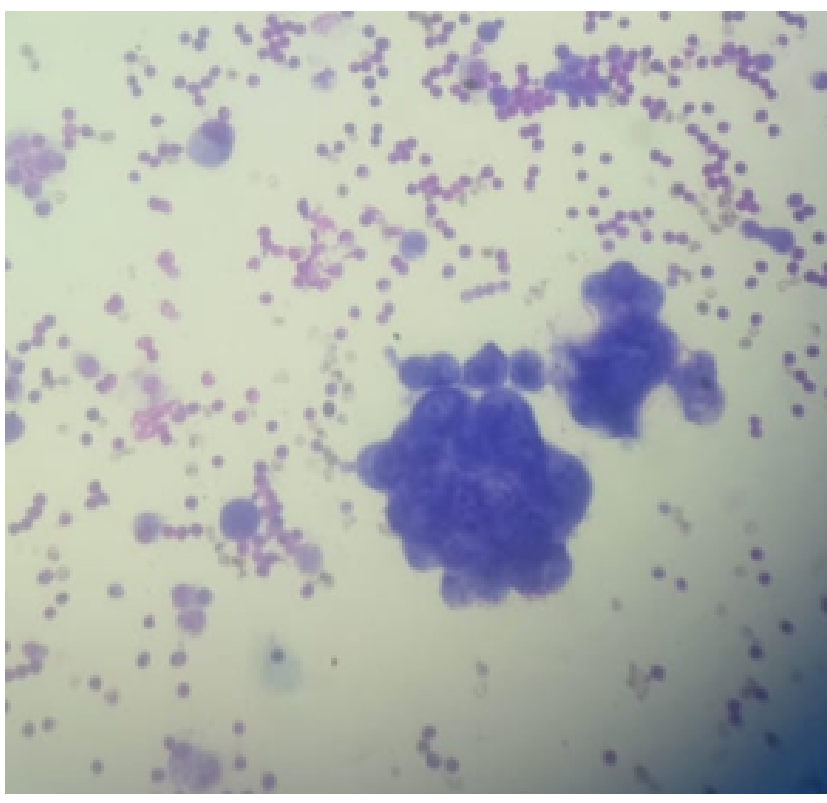

Fig. 7: Centrifuged smear shows three dimensional ball formation in metastatic adenocarcinoma.

On the basis of cytomorphology, metastatic adenocarcioma is most common malignant finding in malignant pleural effusion which was in concordance with the studies conducted by Di Bonito et al ${ }^{10}$ and Hallman et al. ${ }^{11}$

\section{Conclusion}

The present study bring into the limelight the importance of cytological analysis of pleural fluid in establishing the diagnosis. The cytological diagnosis depends to a greater 
extent on the cellularity present in the sediment which is representative of a much larger surface area than that obtained by needle biopsy. Thus, any patients presenting with an undiagnosed pleural effusion to the clinician should be subjected to fluid analysis for preliminary diagnosis and further management.

\section{Source of Funding}

None.

\section{Conflict of Interest}

None.

\section{References}

1. Prasaad PR, Rao BG, Suresh N. Analytical and Cytological Study of Effusions. IOSR J Dent Med Sci. 2016;15(07):83-7.

2. Koss LG, Melamed MR. Koss' diagnostic cytology and itshistopathologic bases. vol. 1. Lippincott Williams \& Wilkins; 2006

3. Sharma M, Sharma A, Khajuria A, Gandhi S. Evaluation of Pathological Body Fluids: An Important Diagnostic Aid. Indian J Basic Appl Med Res - Diagn Res. 2017;6(2):18-24.

4. Sahn SA. Pleural Effusions of Extravascular Origin. Clin Chest Med. 2006;27(2):285-308

5. Gojiya P, Goswami A, Shah S. Cytological Study of Pleural Effusions and its Utility in Clinical Approach. Ann Pathol Lab Med. 2017;4(4):A442-5.
6. Hathila R, Dudhat R, Saini P, Italiya S, Kaptan K, Shah M. Diagnostic importance of serous fluid examination for detection of various pathological conditions-A study of 355 cases. Int J Med Sci Public Health. 2013;2(4):975-9.

7. Kiyawat P, Varma AV, Chakrabarti PR, Malukani K, Singh S. Cytological Analysis of Pleural and Peritoneal Fluids: A Two Year Study in Tertiary Health Care Centre. Saudi J Med. 2018;3(4):13641.

8. Arora I. Cytological Analysis of Pleural Fluid and Ascitic Fluid - A Study from Rural Tertiary Care Hospital, Chamba (H.P). IOSR J Dent Med Sci (IOSR-JDMS). 2018;17(7):75-81.

9. Prasaad PR, Rao BG, Suresh N. Analytical and Cytological Study of Effusions. IOSR J Dent Med Sci. 2016;15(07):83-7.

10. Dibonito L, Falconieri G, Colautti I, Bonifacio D, Dudine S. The positive pleural effusion. A retrospective study of cytopathologic diagnoses with autopsy confirmation. Acta Cytol. 1992;36(3):329-32.

11. Hallman JR, Geisinger KR. Cytology of fluids from pleural, peritoneal and pericardial cavities in children. A comprehensive survey. Acta Cytol. 1994;38(2):209-17.

\section{Author biography}

Lekha M B Assistant Professor

Manjunatha Y A Professor and HOD

Cite this article: Lekha M B, Manjunatha Y A. Analysis of Pleural

fluid cytology: A one year study in tertiary care centre. IP Arch

Cytol Histopathology Res 2020;5(3):199-202. 